\title{
Design and CFD analysis of baffles of fuel tanker trucks for normal and grade highway conditions
}

\section{Nafees Ahmad* and Mehul Varshney}

Department of Mechanical Engineering,

Zakir Husain College of Engineering and Technology,

Aligarh Muslim University,

Aligarh, 202002, Uttar Pradesh, India

Email: nafeesahmad0059@gmail.com

Email: mehulvarshney@zhcet.ac.in

*Corresponding author

\section{Mohammad Haani Farooqi}

Fluid Mechanics and Energetics Department,

Ecole Centrale de Nantes,

Nantes 44300, France

Email: haanifarooqi@zhcet.ac.in

\begin{abstract}
Liquid sloshing is a kind of wave motion inside a partially filled tank. Fluid sloshing affects the stability of fuel tanker truck, because of the movement of the centre of gravity during different dynamic conditions on normal as well as on the grade highways. Hence, controlling sloshing is of prime importance for the prevention of accidents and casualties. For the present work, the tanker truck filled with kerosene fuel has been considered. The baffles are designed to control the phenomenon of sloshing to a maximum extent. The computational fluid dynamics (CFD) analysis of the tank with and without baffles is performed using Fluent ${ }^{\circledR}$ to study the amplitude of sloshing at different time instants. The baffles are designed in a way to ensure no hindrance during loading and unloading of the tanker truck.
\end{abstract}

Keywords: computational fluid dynamics; CFD; kerosene sloshing; rollover; tanker truck; baffles.

Reference to this paper should be made as follows: Ahmad, N., Varshney, M. and Farooqi, M.H. (2020) 'Design and CFD analysis of baffles of fuel tanker trucks for normal and grade highway conditions', Int. J. Forensic Engineering and Management, Vol. 1, No. 1, pp.76-89.

Biographical notes: Nafees Ahmad is a final year undergraduate student, pursuing BTech in Mechanical Engineering from the Zakir Husain College of Engineering and Technology, Aligarh Muslim University, India. His research interests are in the field of automobile engineering, pollution control and HVAC. He is the Secretary of the Club SAE-ZHCET and leading the Powertrain Department of ZHCET Formula Racing Team since 2016 and participated in Formula Student UK 2018 at Silverstone Circuit. He was presenting author of four research works presented in different international conferences including, APS March Meeting 2019, FISITA World Automotive Congress 2018, etc. He also has one Indian patent in the field of emission control. 
Mehul Varshney is a Research scholar in the Department of Mechanical Engineering at Zakir Husain College of Engineering and Technology, Aligarh Muslim University, India. He graduated in Mechanical Engineering, in 2018. His research activity is mainly involved in the field of computational fluid dynamics and thermal science in aeronautics and space research projects. He has authored and co-authored more than six research papers, and also several other publications. He has experience of internship in well-reputed companies like the Volkswagen India and Mercedes-Benz R\&D India.

Mohammad Haani Farooqi is a Master's student of Energetics and Propulsion at Fluid Mechanics and Energetics Department, Ecole Centrale de Nantes, France. He completed his Bachelor's degree from the Zakir Husain College of Engineering and Technology, Aligarh Muslim University, in 2016. He was a powertrain member of the ZHCET Formula Racing and participated in Formula Student UK 2016. His primary interest is in the field of fluid mechanics and automobile engineering.

This paper is a revised and expanded version of a paper entitled 'Designing baffles of fuel tanker trucks to prevent rollover', presented at 15th International Conference on Humanizing Work and Work Environment, HWWE2017, Aligarh Muslim University, 8-10 December 2017.

\section{Introduction}

India being the world's third-largest importer of oil, distribute its oil products throughout the country mainly by tanker trucks. According to 2016 open government data survey of India, about 202.9 million metric tons of crude oil was imported by India in 2015-2016. During transportation, various accidents have occurred, resulting in loss of life and property. In those accidents, rollover instability was one of the major causes. A study by Department of Transportation, USA (Pape et al., 2008) has reported that the average number of tanker rollover is about 1,265 annually in the USA, which accounts for $36.2 \%$ of the total number of heavy vehicle highway accidents. According to the data collected by Statistics Canada (Woodrooffe, 2000), it is shown that $83 \%$ of vehicle rollover accidents on the highway are caused by tanker trucks. There are many reasons responsible for tanker accidents such as environmental factors, driver behaviour, over speeding, tyre burst, but the most common one is liquid sloshing (Kwon, 2011; Kang, 2001). According to the international guideline related with transportation of dangerous materials, for minimising risks and to maintain the internal pressure below safe limits, the tanker trucks are not filled up to the brim with the liquid to be transported. To prevent the free movement of the fluid and to minimise the effect of sloshing, internal barriers called baffles are used. Owing to advancement in computational technology, various problems on liquid sloshing have been studied, and several investigations on the effect of baffles on sloshing have been done in past years (Akyildız and Ünal, 2006). Eswaran et al. (2009) performed the numerical analysis and verified the results experimentally for the sloshing waves inside baffled and unbaffled cubic tank. Salem et al. (2009) gave the literature review of the fluid-container interactions, with the main focus on parameters that affect the stability of partly filled tanker trucks under various manoeuvres. Since 1965, many studies have been done to model the sloshing behaviour inside the partially filled tanker 
trucks to optimise the shape and position of baffles (Liu and Lin, 2009). Numerical and computational fluid dynamics (CFD) study has been performed during braking and lane change manoeuvres of a tanker truck to evaluate the effect of fluid fill level, the position of baffles and shape of the tank (Cheli et al., 2013). For the quick prediction of rollover instability, a quasi-static roll plane model has been developed for a partially filled tank to calculate the forces and moments associated with the free liquid surface movement according to the longitudinal and lateral acceleration provided in the pitch plane and roll plane, respectively (Rakheja and Ranganathan, 1993). By using the law of conservation of momentum with a non-inertial frame of reference attached to the tank, equation for the slope of the free liquid surface has been derived by the help of free body diagram of the tank as shown in Figure 1.

$$
\tan \varnothing=\frac{\frac{a_{z}}{g}-\theta}{1+\frac{a_{z}}{g}}, \quad \tan \varnothing=\frac{\frac{a_{x}}{g}-\theta_{p}}{1+\frac{a_{x}}{g}}
$$

Figure 1 Schematic free body diagram indicating the shifting of the centre of gravity (CG) and direction of force during cornering of a tanker truck

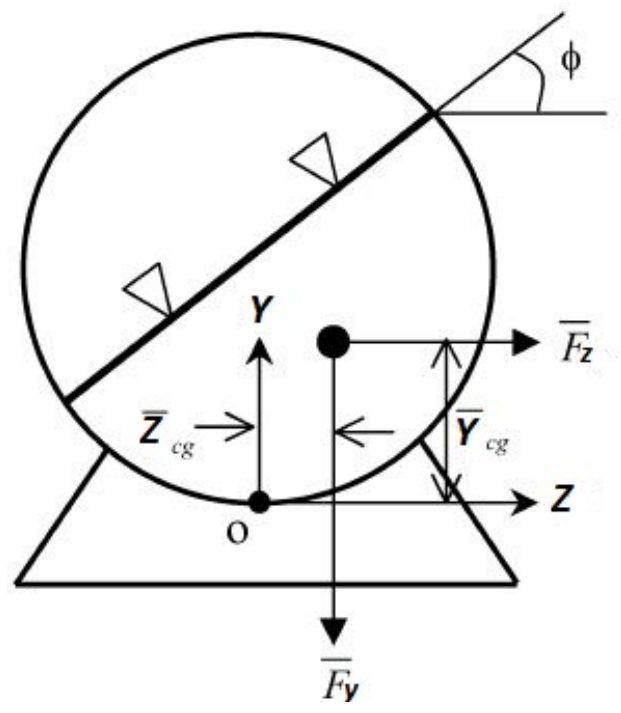

For a given lateral acceleration, the resulting forces and turning moment can be calculated by using the following equations:

$$
\begin{aligned}
& F_{Z}=m *\left(a_{z} g\right) ; \quad F_{y}=m g \\
& M_{x}=F_{y} * Z_{c g}+F_{Z} * Y_{c g}
\end{aligned}
$$

After an experimental investigation, Lloyd et al. (2002) and Belakroum et al. (2010) found that during $40 \%$ to $70 \%$ liquid loading condition, reduction in overall height of CG of the tank takes place but during the cornering and braking, the resultant forces and rolls moment lead to a reduction in rolling stability and created unbalancing. The present work focuses on the design of lateral, longitudinal and bisectional baffles for a 
cylindrical-shaped tanker truck and provides the best suitable baffle design for the safe and trouble-free transportation of liquid on normal as well as grade highways.

When tanker trucks go for the cornering on a normal highway, the liquid bulk moves frequently and exert the force on the side wall. During the uphill on grade highway or in hilly areas, the fluid bulk exerts high forces on the rear wall of the tank while during downhill the sudden forces acting on front wall cause unbalancing and create the loss of directional control due to immediate impact and vibrations. Therefore, the CFD simulation is carried out for the design of baffles in such a way that tanker truck can moves smoothly on normal as well as grade highways. For the case of uphill and downhill, simulation is carried out by considering a critical condition that is $35 \%$ grade (20 degrees) areas like Baldwin Street, Dunedin, New Zealand, and Waipio Rd., Honokaa, Hawaii.

\section{Validation}

For solving the actual problem, a validation case has been considered to examine the motion of the free surface of the liquid in a partially filled fuel rectangular tank (Singal et al., 2014). The same approach has been used to solve the problem of the tanker truck. The result showed a close match, as can be seen from Figure 2.

Figure 2 Liquid interface at, (a) $t=1.25 \sec (b) t=1.25 \sec (c) t=1.25 \sec (d) t=1.25 \sec$ (see online version for colours)

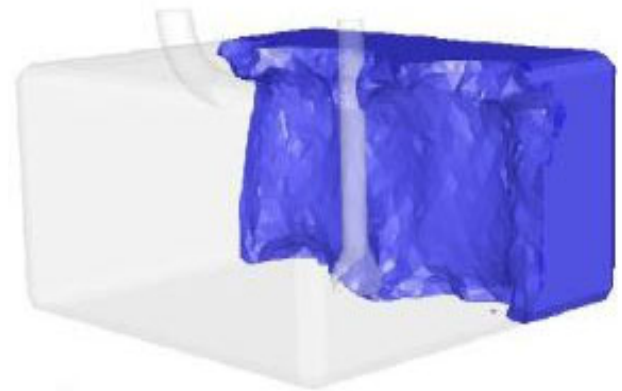

(a)

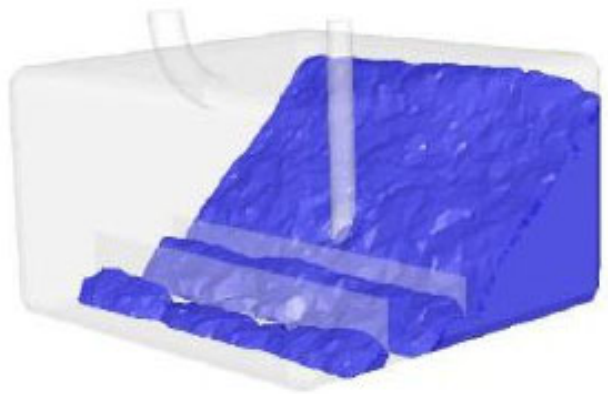

(c)

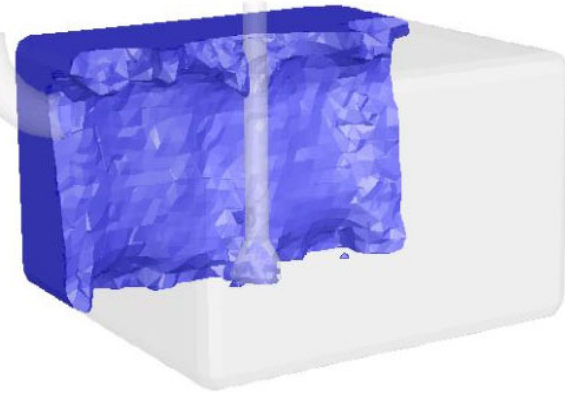

(b)

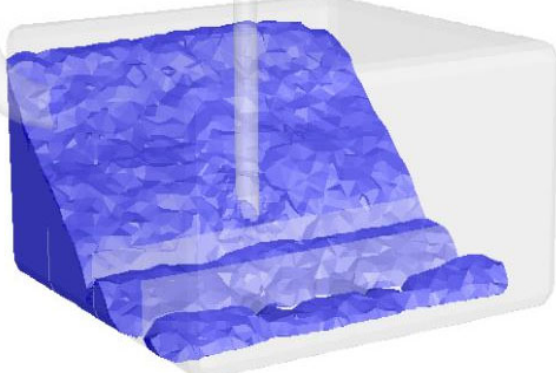

(d)

Note: (a) and (c) represents the result obtained by Singal et al. (2014) and (b) and (d) represent the results obtained during validation. 


\section{Methodology}

The following cases have been considered for the tanker truck:

a without baffles during acceleration

b without baffles during cornering

c lateral baffles during cornering

d lateral baffles and one longitudinal baffle during acceleration

e lateral baffles and one longitudinal baffle during cornering

f lateral baffles and two longitudinal baffles during cornering

g lateral and bisectional baffle during cornering (at $40 \%$ loading condition)

$\mathrm{h}$ lateral and bisectional baffle during cornering (at 70\% loading condition)

i without baffles during uphill on grade highways

j lateral and bisectional baffles during uphill on grade highways

$\mathrm{k} \quad$ without baffles during downhill on grade highways

1 lateral and bisectional baffles during downhill on grade highways

$\mathrm{m}$ to check the design of bisectional baffle during unloading of a tanker truck.

The following assumptions have been made:

1 For the possible critical case, the tank acceleration is assumed to be $9.8 \mathrm{~m} / \mathrm{s}^{2}$ during acceleration, braking and cornering on normal highways, while during uphill and downhill it is expected to accelerate at $9.8 \mathrm{~m} / \mathrm{s}^{2}$ and $5 \mathrm{~m} / \mathrm{s}^{2}$, respectively.

2 Density and viscosity of kerosene are $750 \mathrm{~kg} / \mathrm{m}^{3}$ and $0.0024 \mathrm{~kg} / \mathrm{m}-\mathrm{s}$, respectively.

3 The material of the tank and baffles is defined as aluminium.

\section{Design}

The 3D geometry of the tank is CAD generated with the following specifications:

1 Cylindrical tank $10 \mathrm{~m}$ long with diameter $2.5 \mathrm{~m}$ have been considered in the study.

2 Lateral baffles with central and semi-circular circumferential holes of diameter $0.5 \mathrm{~m}$ respectively, whereas longitudinal baffles with a bottom hole of diameter $0.5 \mathrm{~m}$ (see Figure 3).

3 The bisectional baffle is $10 \mathrm{~m}$ long, with circular and rectangular holes, as shown in Figure 4.

The holes on the bisectional baffle are designed in such a way that during loading of the fuel tanker truck, the bottom part of the tank should be filled first to distribute the bulk evenly. Generally, in tanker trucks, there are individual top inlet manholes of minimum 
diameter $0.25 \mathrm{~m}$ for each compartment to provide trouble-free loading. So, during the top loading, firstly the fuel will be collected on the bisectional baffle then by the help of four holes with $0.25 \mathrm{~m}$ diameter on the bisectional baffle for each compartment keeps the volume flow rate constant and the rectangular holes of dimension $(0.5 \mathrm{~m} * 0.1 \mathrm{~m})$ are also given to prevent the kerosene accumulation at different corners as shown in Figure 4.

Figure 3 Tanker with, (a) lateral and longitudinal baffles (b) lateral and bisectional baffle (see online version for colours)

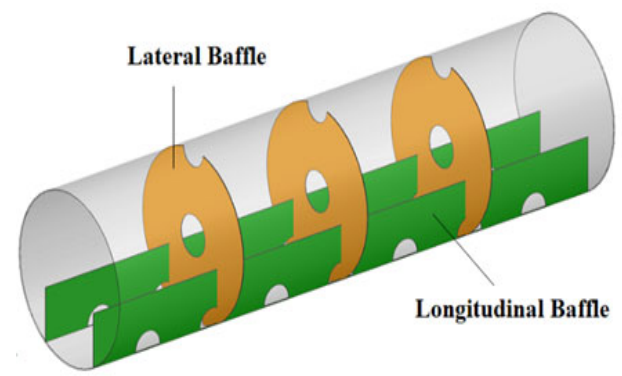

(a)

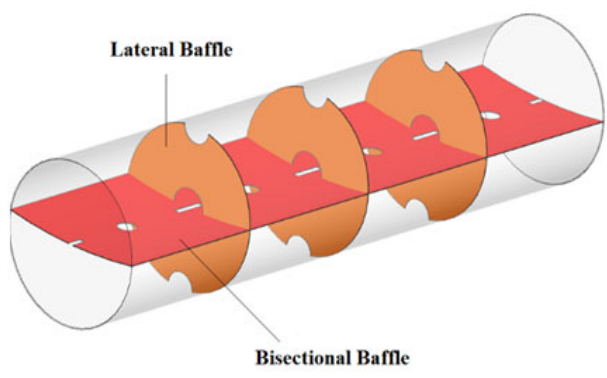

(b)

Figure 4 Top view of the bisectional baffle

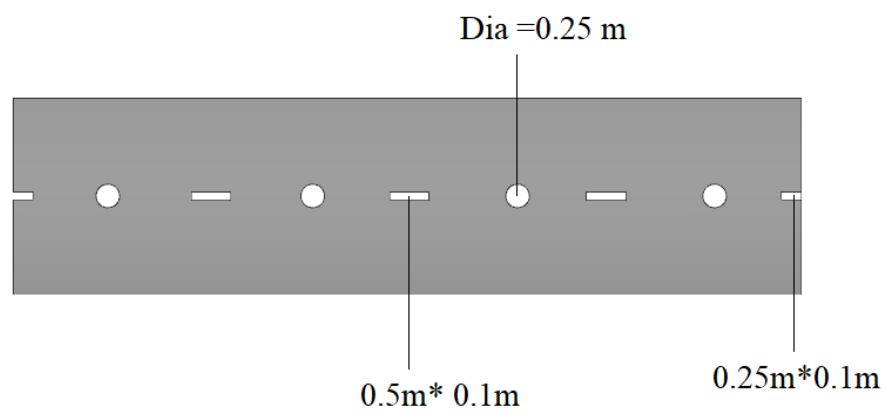

As per the CFD and experimental analysis, to prevent the accumulation of fluid on the bisectional baffle the slope needed to be $9^{\circ}$. The shape of the bisectional baffle is decided to ensure that not a single drop of kerosene would accumulate over the bisectional baffle. It was found that when the shape of the bisectional baffle was flat, some of the kerosene liquid got collected at different corners of the tank. Hence, curved bisectional baffle making a slope of $9^{\circ}$ (as shown in Figure 5), is incorporated such that every single drop of kerosene liquid should come down to the base of the tank.

Figure 5 Back view of the bisectional baffle (see online version for colours)

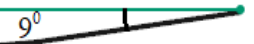




\section{Computational study and modelling}

ICEM-CFD was used to mesh the computational domain of the tank. Unstructured mesh with tetrahedral elements was used with the number of elements as 0.88 million and number of nodes as 0.14 million (see Figure 6).

Figure 6 Mesh of the computational domain (see online version for colours)
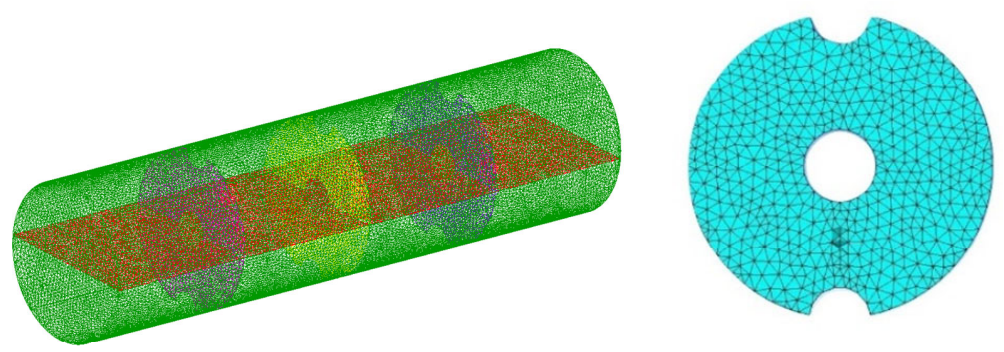

ANSYS FLUENT® 16.0 commercial package was used to perform the CFD simulations by using volume of fluid (VOF) multi-phase model, $k$-epsilon viscous model. The energy equation was turned-off because there was no exchange of heat energy, or the process was assumed isothermal.

\subsection{Governing equations}

- continuity equation:

$$
\nabla \cdot \vec{v}=0
$$

- momentum equation:

$$
\frac{\partial}{\partial t}(\rho \vec{v})+\nabla \cdot(\rho \vec{v} \vec{v})=-\nabla p+\nabla \cdot\left[\mu\left(\nabla \vec{v}+\nabla \vec{v}^{T}\right)\right]+\rho \vec{g}+\vec{F}
$$

- volume fraction equation:

$$
\frac{1}{\rho_{q}}\left[\frac{\partial}{\partial t}\left(\alpha_{q} \rho_{q}\right)+\nabla \cdot\left(\alpha_{q} \rho_{q} \vec{v}_{q}\right)=S_{\alpha_{q}}+\sum_{p=1}^{n}\left(\dot{m}_{p q}-\dot{m}_{q p}\right)\right] \text {. }
$$

\subsection{Solver details}

Pressure-velocity coupling scheme

Spatial discretisation of gradients

Spatial discretisation of pressure

Spatial discretisation of momentum

Spatial discretisation of volume fraction

Transient formulation
Fractional step (NITA)

Green-Gauss node-based

Body force weighted

Second order upwind

Geo-reconstruct

First order implicit 


\section{Results and discussion}

Case study for the free liquid surface interface of the kerosene in the tanker truck during different dynamic conditions on normal highways at $40 \%$ loading condition and on $35 \%$ $\left(20^{\circ}\right)$ grade highways at $70 \%$ loading condition.

Figure 7 (a) Tanker without baffles during acceleration (b) Tanker without baffles during cornering (c) Tanker with lateral baffles during cornering (d) Tanker with lateral and one longitudinal baffle during acceleration (e) Tanker with lateral baffles and one longitudinal baffle during cornering (f) Tanker with lateral and two longitudinal baffles during cornering $(\mathrm{g})$ Tanker truck with lateral and bisectional baffles during cornering (h) Tanker truck with lateral and bisectional baffle during cornering at $70 \%$ loading condition (i) Tanker truck without baffles during uphill $\nearrow$ (j) Tanker truck with lateral and bisectional baffles during uphill $\nearrow(\mathrm{k})$ Tanker truck without baffles downhill $\searrow$ (l) Tanker truck with lateral and bisectional baffle downhill $\searrow$ (m) To check the design of bisectional baffle during unloading of fuel (with kerosene layer of $0.15 \mathrm{~m}$ above the bisectional baffle) (see online version for colours)

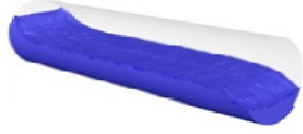

$\mathrm{t}=0.30 \mathrm{sec}$

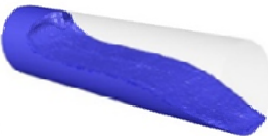

$\mathrm{t}=0.60 \mathrm{sec}$

(a)

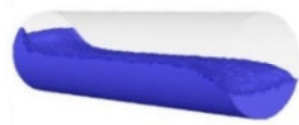

$\mathrm{t}=0.30 \mathrm{sec}$

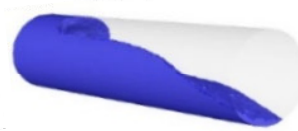

$\mathrm{t}=0.60 \mathrm{sec}$

(b)

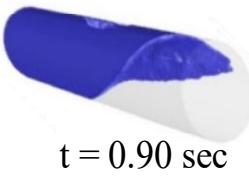

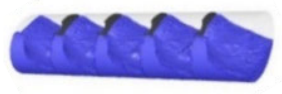

$\mathrm{t}=0.30 \mathrm{sec}$

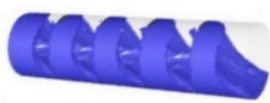

$\mathrm{t}=0.60 \mathrm{sec}$

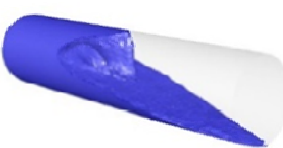

$\mathrm{t}=0.90 \mathrm{sec}$

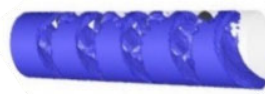

$\mathrm{t}=0.90 \mathrm{sec}$

(c)

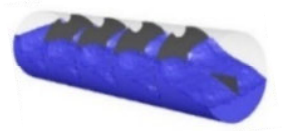

$\mathrm{t}=0.30 \mathrm{sec}$

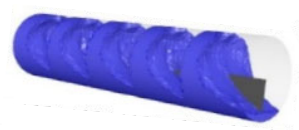

$\mathrm{t}=0.60 \mathrm{sec}$

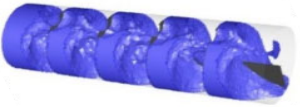

$$
\mathrm{t}=0.90 \mathrm{sec}
$$

(d)
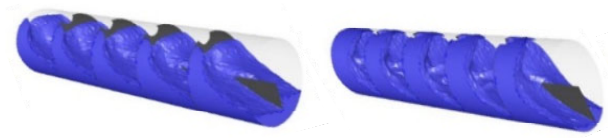

$\mathrm{t}=0.30 \mathrm{sec}$

$\mathrm{t}=0.60 \mathrm{sec}$

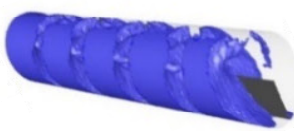

$\mathrm{t}=0.90 \mathrm{sec}$
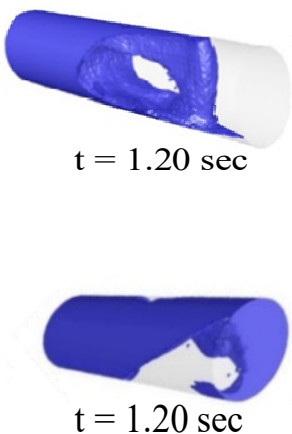

$\mathrm{t}=1.20 \mathrm{sec}$

$\mathrm{t}=1.20 \mathrm{sec}$

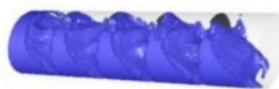

$\mathrm{t}=1.20 \mathrm{sec}$

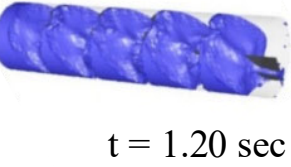

(e)

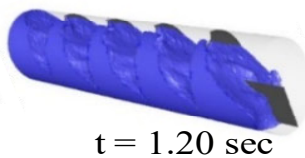


Figure 7 (a) Tanker without baffles during acceleration (b) Tanker without baffles during cornering (c) Tanker with lateral baffles during cornering (d) Tanker with lateral and one longitudinal baffle during acceleration (e) Tanker with lateral baffles and one longitudinal baffle during cornering (f) Tanker with lateral and two longitudinal baffles during cornering $(\mathrm{g})$ Tanker truck with lateral and bisectional baffles during cornering (h) Tanker truck with lateral and bisectional baffle during cornering at $70 \%$ loading condition (i) Tanker truck without baffles during uphill $\nearrow$ (j) Tanker truck with lateral and bisectional baffles during uphill $\nearrow(\mathrm{k})$ Tanker truck without baffles downhill $\searrow$ (l) Tanker truck with lateral and bisectional baffle downhill $\searrow$ (m) To check the design of bisectional baffle during unloading of fuel (with kerosene layer of $0.15 \mathrm{~m}$ above the bisectional baffle) (continued) (see online version for colours)

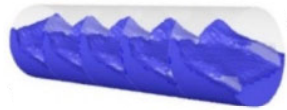

$\mathrm{t}=0.30 \mathrm{sec}$

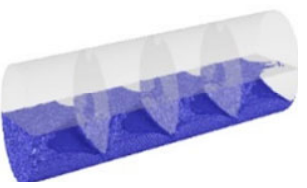

$\mathrm{t}=0.30 \mathrm{sec}$

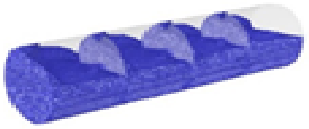

$\mathrm{t}=0.25 \mathrm{sec}$

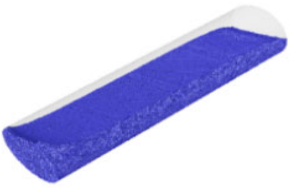

$\mathrm{t}=0.25 \mathrm{sec}$

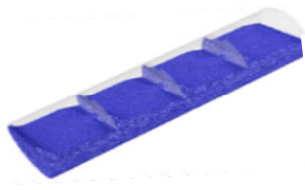

$\mathrm{t}=0.25 \mathrm{sec}$

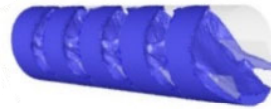

$\mathrm{t}=0.60 \mathrm{sec}$

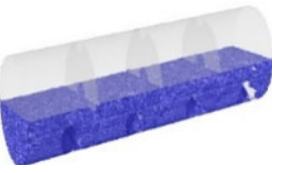

$\mathrm{t}=0.60 \mathrm{sec}$

(g)

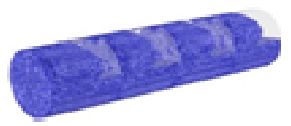

$\mathrm{t}=0.50 \mathrm{sec}$

(h)

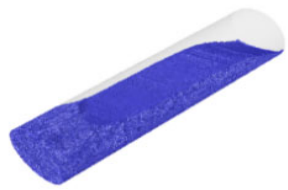

$\mathrm{t}=0.50 \mathrm{sec}$

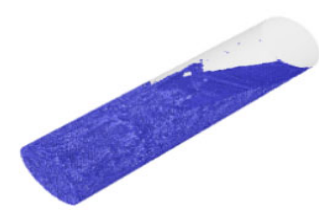

$\mathrm{t}=0.75 \mathrm{sec}$

(i)

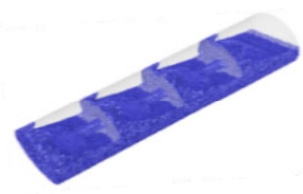

$\mathrm{t}=0.50 \mathrm{sec}$

(f)

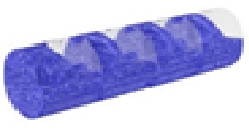

$\mathrm{t}=0.75 \mathrm{sec}$
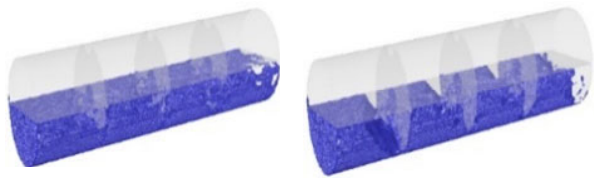

$\mathrm{t}=1.20 \mathrm{sec}$

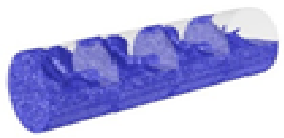

$\mathrm{t}=1.0 \mathrm{sec}$

$$
\mathrm{t}=0.90 \mathrm{sec}
$$

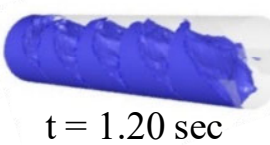

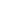

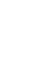


Figure 7 (a) Tanker without baffles during acceleration (b) Tanker without baffles during cornering (c) Tanker with lateral baffles during cornering (d) Tanker with lateral and one longitudinal baffle during acceleration (e) Tanker with lateral baffles and one longitudinal baffle during cornering (f) Tanker with lateral and two longitudinal baffles during cornering $(\mathrm{g})$ Tanker truck with lateral and bisectional baffles during cornering (h) Tanker truck with lateral and bisectional baffle during cornering at $70 \%$ loading condition (i) Tanker truck without baffles during uphill $\nearrow$ (j) Tanker truck with lateral and bisectional baffles during uphill $\nearrow(\mathrm{k})$ Tanker truck without baffles downhill $\searrow$ (1) Tanker truck with lateral and bisectional baffle downhill $\searrow$ (m) To check the design of bisectional baffle during unloading of fuel (with kerosene layer of $0.15 \mathrm{~m}$ above the bisectional baffle) (continued) (see online version for colours)

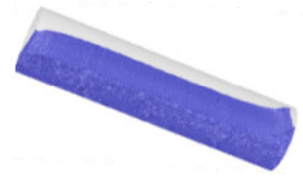

$\mathrm{t}=0.25 \mathrm{sec}$

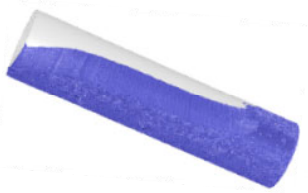

$\mathrm{t}=0.50 \mathrm{sec}$

$\mathrm{t}=0.75 \mathrm{sec}$

(k)

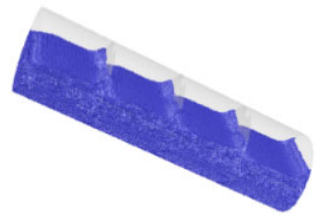

$\mathrm{t}=0.25 \mathrm{sec}$

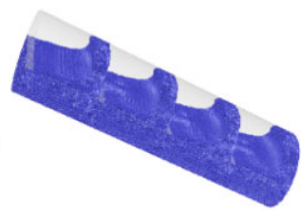

$\mathrm{t}=0.50 \mathrm{sec}$

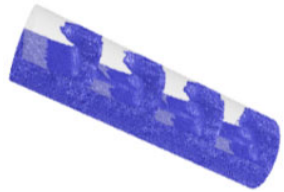

$\mathrm{t}=0.75 \mathrm{sec}$

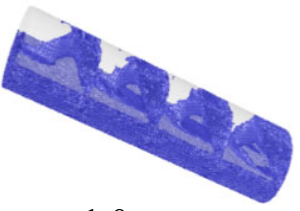

$\mathrm{t}=1.0 \mathrm{sec}$

(1)

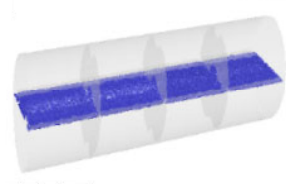

$\mathrm{t}=0 \mathrm{sec}$ $\mathrm{t}=2.0 \mathrm{sec}$
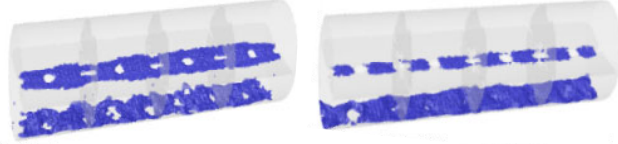

$\mathrm{t}=5.0 \mathrm{sec}$

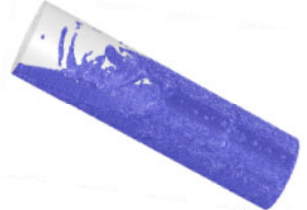

$\mathrm{t}=1.0 \mathrm{sec}$

(m)

The motion of kerosene inside the tanker is found to be changed depending on the orientation of baffles. Initially, the fluid motion without baffles was observed during acceleration, braking and cornering. It was found that during acceleration and braking with four lateral baffles inside the tanker, the fluid did not hit the front wall, which reduces the impact and helps in comfortable braking without skidding. During turning while braking, the kerosene rotates inside the tanker which induces high cornering moment that may lead to the toppling of the tanker. When four lateral baffles are used, there was a rotation of kerosene in each compartment. Although the cornering moment was found to be lower than the initial value, the magnitude was significantly higher. Using a baffle is passing through the centre longitudinally, further reduced the turning moment, bringing it down to the safe range. The turning moment further reduced by using the two longitudinal baffles, which caused the kerosene to rise from both the 
directions inside the tanker after striking the longitudinal baffle, thereby cancelling out the turning moment.

After implementing the bisectional baffle, the movement of kerosene liquid is minimum in comparison to all the cases during different dynamic conditions on normal highways as with a small shift in CG. There is a massive reduction of forces and turning moment on the side walls. When the volume of kerosene is just less than half of the tank, bisectional baffles reduce the free space for movement of the bulk, which results in a minimal change in position of the CG as shown in case $\mathrm{g}$. When volume of the kerosene is more than half of the tank then the bulk which is below the bisectional baffle is always at rest due to no free space for movement, while in the upper part kerosene liquid slosh but overall CG is balanced by the bulk below bisectional baffle as showed in case $h$. During uphill and downhill, in case of the tank without baffle, the liquid volume hits the front and rear wall respectively and exerts a sudden force which makes the tanker truck unbalance. Bisectional baffle resists the motion of kerosene, which decreases the amount of sudden force on the front and rear wall. Improvised design of bisectional baffle prevents fuel accumulation and helps in trouble-free unloading of fuel from the tanker at rest. CFD simulation shown in case $\mathrm{m}$ shows that during unloading, whole kerosene bulk comes down to the bottom of the tank within $10 \mathrm{sec}$, which proves that the design of baffle is much effective.

\section{Conclusions}

While comparing the tank without baffles and tank with four lateral and a bisectional baffle, it has been observed that during cornering on normal highways there was $50 \%$ and $130 \%$ reduction in maximum force and turning moment acting on tank wall, respectively (see Figures 8 and 9) and this is the maximum reduction among all the cases studied for different baffle orientations comparison. During uphill and downhill, bisectional baffle resists the kerosene liquid to move beyond it so change in the CG of the whole system is considerably small in comparison to the tanker with longitudinal baffles. For uphill and downhill motion, the peak force for the tanker without baffles is very high in between 0.7-0.8 seconds of fuel motion inside the tank which results in impact loading causing sudden instability, making the vehicle more prone to accident. The peak force is found to reduce to a greater extent for both uphill and downhill motion by bisectional baffles. The low-intensity impact is observed during uphill motion making it safer for truck motion (see Figure 10). Although the constant increase in force is found during the downhill, there is no sudden impact, and the graph is smoother, which makes it easy for the driver to handle the truck (see Figure 11). Bisectional baffle helps in reducing the sloshing phenomenon to a great extent by constraining the motion of liquid in a fixed space. This type of baffle design will help in countering the problems caused by sloshing in automotive as well as transportation industries. It can be inferred that the use of baffles can significantly reduce the force and cornering moment acting on the tank wall which is the primary cause of toppling and thereby will minimise accidents and casualties caused by tanker truck rollovers. 
Figure 8 Graph of force exerted on the side wall at different time instants during cornering (see online version for colours)

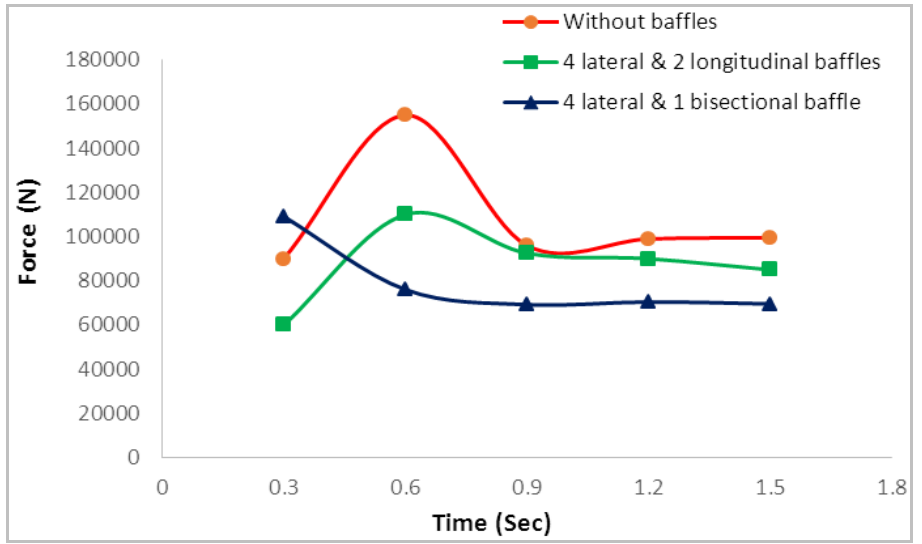

Figure 9 Graph of turning moment acting at different time instants during cornering (see online version for colours)

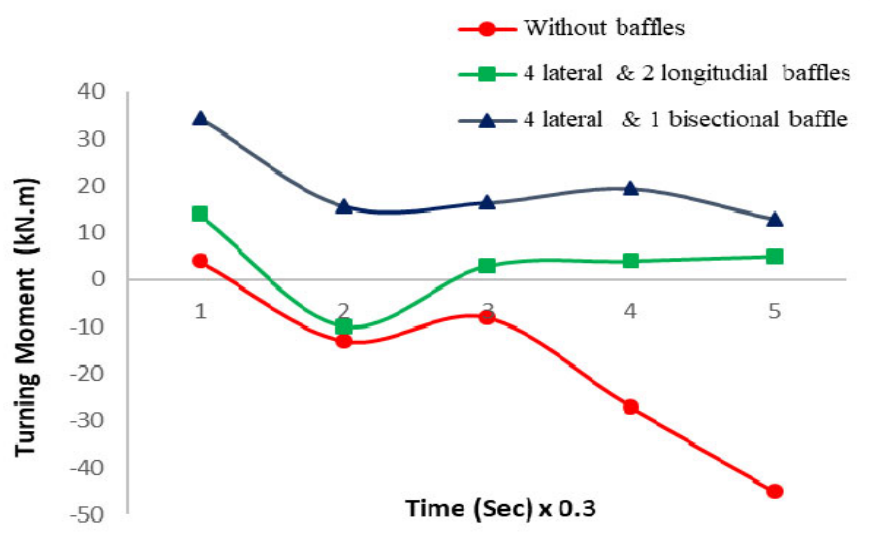

Figure 10 Graph of force exerted on the rear wall at different time instants during uphill (see online version for colours)

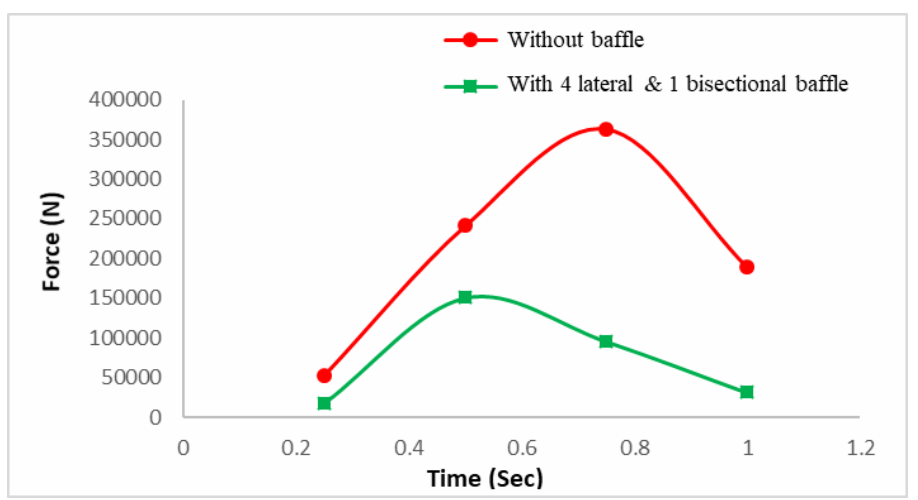


Figure 11 Graph of force exerted on the front wall at different time instants during the downhill (see online version for colours)

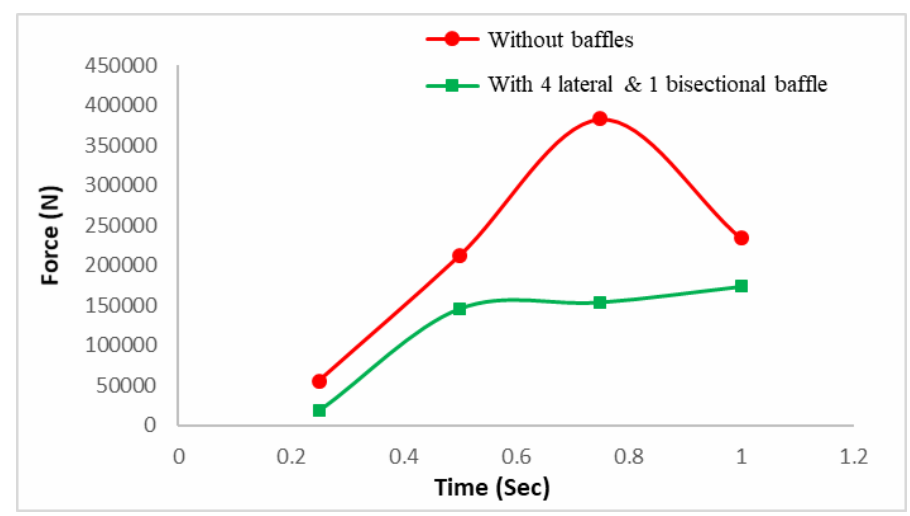

\section{References}

Akyildı, H. and Ünal, N.E. (2006) 'Sloshing in a three-dimensional rectangular tank: numerical simulation and experimental validation', Ocean Engineering, Vol. 33, No. 16, pp.2135-2149.

Belakroum, R., Kadja, M., Mai, T.H. and Maalouf, C. (2010) 'An efficient passive technique for reducing sloshing in rectangular tanks partially filled with liquid', Mechanics Research Communications, Vol. 37, No. 3, pp.341-346.

Cheli, F., D'Alessandro, V., Premoli, A. and Sabbioni, E. (2013) 'Simulation of sloshing in tank trucks', International Journal of Heavy Vehicle Systems, Vol. 20, No. 1, pp.1-18.

Eswaran, M., Saha, U.K. and Maity, D. (2009) 'Effect of baffles on a partially filled cubic tank: numerical simulation and experimental validation', Computers \& Structures, Vol. 87, No. 3, pp.198-205.

Kang, X. (2001) Optimal Tank Design and Directional Dynamic Analysis of Liquid Cargo Vehicles Under Steering and Braking, Doctoral dissertation, Concordia University.

Kwon, C. (2011) 'Conditional value-at-risk model for hazardous materials transportation', in Simulation Conference (WSC), Proceedings of the 2011 Winter, IEEE, December, pp.1703-1709.

Liu, D. and Lin, P. (2009) 'Three-dimensional liquid sloshing in a tank with baffles', Ocean Engineering, Vol. 36, No. 2, pp.202-212.

Lloyd, N., Vaiciurgis, E. and Langrish, T.A.G. (2002) 'The effect of baffle design on longitudinal liquid movement in road tankers: an experimental investigation', Process Safety and Environmental Protection, Vol. 80, No. 4, pp.181-185.

Pape, D.B., McMillan, N., Greenberg, A., Mayfield, H., Chitwood, J.C., Winkler, C.B., ... Harback, K. (2008) 'Benefits and costs of four approaches to improving rollover stability of cargo tank motor vehicles', Transportation Research Record, Vol. 2066, No. 1, pp.114-121.

Rakheja, S. and Ranganathan, R. (1993) 'Estimation of the rollover threshold of heavy vehicles carrying liquid cargo: a simplified approach', International Journal of Heavy Vehicle Systems, Vol. 1, No. 1, pp.79-98.

Salem, M.I., Mucino, V.H., Saunders, E., Gautam, M. and Lozano-Guzman, A. (2009) 'Lateral sloshing in partially filled elliptical tanker trucks using a trammel pendulum', International Journal of Heavy Vehicle Systems, Vol. 16, Nos. 1-2, pp.207-224.

Singal, V., Bajaj, J., Awalgaonkar, N. and Tibdewal, S. (2014) 'CFD analysis of a kerosene fuel tank to reduce liquid sloshing', Procedia Engineering, Vol. 69, pp.1365-1371.

Woodrooffe, J. (2000) Evaluation of Dangerous Goods Vehicle Safety Performance, Report TP, No. 13678-E. 


\section{Nomenclatures}

\begin{tabular}{ll}
\hline Symbol & \\
\hline$\theta$ & Roll angle \\
$\theta_{p}$ & Pitch angle \\
$a_{z}$ & Lateral acceleration \\
$a_{x}$ & Longitudinal acceleration \\
$g$ & Acceleration due to gravity \\
$\tan \varnothing$ & The slope of the free liquid surface \\
$F$ & Force \\
$M$ & Turning moment \\
$m$ & Mass \\
$\vec{v}$ & Velocity vector \\
$\rho$ & Density of kerosene \\
$p$ & Pressure \\
$\mu$ & Dynamic viscosity \\
$\dot{m}_{p q}$ & Mass transfer from phase $p$ to phase $q$ \\
$\dot{m}_{q p}$ & Mass transfer from phase $q$ to phase $p$ \\
\hline
\end{tabular}

